\title{
Equine Dermatophytosis: A Survey of Its Occurrence and Species Distribution among Horses in Kaduna State, Nigeria
}

\author{
Magdalene N. Maurice, ${ }^{1}$ Haruna M. Kazeem, ${ }^{1}$ Clara N. Kwanashie, ${ }^{1}$ Nanven A. Maurice, ${ }^{1,2}$ \\ Emmanuel O. Ngbede, ${ }^{3}$ Helen N. Adamu, ${ }^{4}$ Wayuta P. Mshelia, ${ }^{5}$ and Richard E. Edeh ${ }^{5}$ \\ ${ }^{1}$ Department of Veterinary Microbiology, Faculty of Veterinary Medicine, Ahmadu Bello University, PMB 1045, Zaria, \\ Kaduna State, Nigeria \\ ${ }^{2}$ Department of Diagnostics and Extension, National Veterinary Research Institute, PMB 01, Vom, Plateau State, Nigeria \\ ${ }^{3}$ Department of Veterinary Pathology and Microbiology, College of Veterinary Medicine, University of Agriculture, Makurdi, \\ PMB 2373, Benue State, Nigeria \\ ${ }^{4}$ Department of Epidemiology and Medical Statistics, Faculty of Public Health, University of Ibadan, PMB 5017, Oyo State, Nigeria \\ ${ }^{5}$ Department of Veterinary Medicine, Faculty of Veterinary Medicine, Ahmadu Bello University, PMB 1045, Zaria, \\ Kaduna State, Nigeria
}

Correspondence should be addressed to Nanven A. Maurice; mnanven@hotmail.com

Received 26 December 2015; Revised 2 May 2016; Accepted 9 May 2016

Academic Editor: Michael Ivan Lindinger

Copyright (C) 2016 Magdalene N. Maurice et al. This is an open access article distributed under the Creative Commons Attribution License, which permits unrestricted use, distribution, and reproduction in any medium, provided the original work is properly cited.

\begin{abstract}
This study was designed to determine the occurrence and species distribution of dermatophyte from cutaneous skin lesions of horses in Kaduna State, Nigeria. A total of 102 skin scrapings were collected from 102 horses with skin lesions. Mycological studies were carried out using conventional techniques. Dermatophytes were isolated from $18(17.6 \%)$ of the 102 samples collected. The 18 dermatophytes were distributed into 10 different species belonging to Microsporum $(n=5)$ and Trichophyton $(n=5)$ genera. T. verrucosum $(n=4)$ was the most predominant species isolated followed by M. equinum $(n=3)$, T. vanbreuseghemii $(n=2)$, M. gypseum $(n=2)$, and M. canis $(n=2)$. Others include M. fulvum $(n=2)$, T. mentagrophytes $(n=1)$, T. equinum $(n=1), T$. soudanense $(n=1)$, and M. gallinae $(n=1)$. The present study reveals the occurrence of dermatophytes in cutaneous skin lesions of horses in Kaduna State, Nigeria. In addition for the first time in this environment the anthropophilic dermatophyte T. soudanense was isolated from horses. These findings have great economic, veterinary, and public health significance as they relate to the cost of treatment and dissemination of zoonotic dermatophytes.
\end{abstract}

\section{Introduction}

Dermatophytes are cited as the most frequent causes of dermatological problems in domestic animals [1]. They belong to the class Ascomycetes, which are normally located in the stratum corneum, hair shaft, or hoof, where they invade [2]. There are approximately 40 different species of dermatophytes characterized by their capability to digest keratin and divided into three genera: Trichophyton, Microsporum, and Epidermophyton [3]. A wide variety of dermatophytes have been isolated from animals, but a few zoophilic ( $M$. canis, T. mentagrophytes, T. equinum, and T. verrucosum), geophilic (M. gypseum), and anthropophilic dermatophytes
(M. equinum and T. equinum) are reported to frequently cause dermatophytosis in horses $[4,5]$.

The distribution of dermatomycosis, their aetiological agents, and the predominating anatomical infection patterns vary with geographical location, age of the animal, and environmental and cultural factors $[6,7]$. Contagiousness among animal populations, high cost of treatment, difficulty of control measures, and the public health consequences of animal (especially horses) ringworm explain their great importance [4]. The high resistance of the dermatophyte arthroconidia in the environment, colonization of host species, and the confinement of animals in breeding areas are factors that also influence the endemicity of dermatophytosis [4]. 
Lesions arising from dermatophytosis have many adverse effects besides the discomfort and unsightly nuisance (esthetic) [8]. They also prevent the horses from working and interferes with their use in polo, racing, and riding because the horse will not be allowed at shows or other events (because it can transmit it to other horses), thus decreasing the cost value of the horse. Equine dermatophytosis also has considerable zoonotic importance as animals serve as reservoirs for the zoophilic dermatophytes (especially those caused by members of the Microsporum spp. and Trichophyton genera) and their infections [8, 9]. Zoophilic dermatophytes such as T. verrucosum, $M$. canis, T. mentagrophytes, $M$. gypseum, and T. equinum have been reported as important causes of human tinea capitis and tinea corporis in many areas of the world [10]. It has been suggested that the increasing number of reports of infections due to zoophilic dermatophytes in humans is directly linked to the persistence of this fungus in animal reservoirs [10]. Therefore knowledge of their role in cutaneous skin lesions and identification of the species may play an important role in control of outbreaks by establishing the source of infection and thereby plans to manage and control dermatophytosis.

Although dermatophytosis is worldwide in distribution, it is more prevalent in hot humid climates than in cold dry regions $[6,11]$. Despite the high prevalence of dermatophytoses in Nigeria, few studies have been carried out to identify the fungal species causing cutaneous lesions in horses and their prevalence [1]. Equine dermatophytosis has received little attention in Nigeria especially in the northern part of the country where a large population of horses are located and used for festivities (traditional durbar), polo, racing, and pleasure riding $[6,12,13]$. As a result, an actual prevalence figure for tinea in horse is unknown in Kaduna State and Nigeria as a whole. There is therefore urgent need to update our knowledge of the epidemiology of ringworm infection in domestic animals. The aim of this study was to investigate the occurrence and species distribution of dermatophytes from horses with cutaneous lesions suggestive of dermatophytosis in Kaduna State, Nigeria.

\section{Materials and Methods}

2.1. Sample Collection. Samples from 102 horses with cutaneous lesions suggestive of dermatophytosis were collected from March to September 2014. Skin scrapings and hair samples were collected from the margins of the lesions according to the method of Elewski [14]. Whereas generalized lesions of an anatomic location were encountered, multiple (3-4) samples were collected from the different parts of the lesion and pooled together as one sample. Also the lesions were photographed with the aid of a digital camera (Samsung WB30F). Samples were placed in coloured (brown) envelops and transported as dry packet to the Diagnostic Laboratory of the Department of Veterinary Microbiology, Ahmadu Bello University, Zaria, for cultural isolation and identification of dermatophytes.

2.2. Culture and Isolation of Dermatophytes. Sabouraud dextrose agar (SDA) (Oxoid, UK) supplemented with
TABLE 1: Occurrence and distribution of dermatophytes based on anatomical site of lesion among horses with cutaneous skin lesions in Kaduna State, Nigeria.

\begin{tabular}{lcc}
\hline $\begin{array}{l}\text { Anatomical site } \\
\text { of lesion }\end{array}$ & $\begin{array}{c}\text { Number of } \\
\text { samples }\end{array}$ & $\begin{array}{c}\text { Number (\%) of } \\
\text { samples positive } \\
\text { for } \\
\text { dermatophytes }\end{array}$ \\
\hline Saddle area & 15 & $5(33.3)$ \\
Limbs & 20 & $5(25)$ \\
Generalized & 13 & $3(23.1)$ \\
Rump & 5 & $1(20)$ \\
Flank and girth & 25 & $3(12)$ \\
Head & 12 & $1(8.3)$ \\
Neck & 7 & $0(0)$ \\
Wither & 5 & $0(0)$ \\
\hline Total & 102 & $18(17.6)$ \\
\hline
\end{tabular}

chloramphenicol $40 \mathrm{mg} / \mathrm{L}$ (Fluka, UK), cycloheximide $500 \mathrm{mg} / \mathrm{L}$ (Sigma, Germany), and nicotinic acid $(100 \mu \mathrm{g} / \mathrm{mL})$ was used for primary isolation [15]. Culture was carried out on agar plates. Another set of SDA (vitamin-free) was seeded concurrently. The scabs and hair collected were seeded on the medium and the plates incubated at room temperature for 1-4 weeks. The plates were checked for visible fungi growth every other day.

2.3. Identification of Isolates. Pure fungi growths of suspected dermatophytes from the SDA cultures plates were subcultured onto the potatoes dextrose agar (PDA) plates to facilitate sporulation [16] and incubated at room temperature for 1-4 weeks. The fungi were identified based on their colonial morphology on the agar plates and microscopic characteristics (after staining with lactophenol cotton blue and viewing using $\times 10$ and $\times 40$ magnification) with the aid of Fungal Colour Atlas [17]. Slide culture preparations were also made for isolates that were not identified from PDA culture stained slides. Hair perforation test was used as a diagnostic aid for some isolates [16]. Characteristics used for the identification of dermatophytes in the study included colony pigment, texture, growth rate, and morphological features such as macroconidia, microconidia, and nodular organs as well as nutritional characteristic such as amino acid requirement and growth in 5\% salt supplemented SDA to differentiate $T$. mentagrophytes from other Trichophyton species [18, 19].

\section{Results}

The study examined 102 horses comprising 53 males and 49 females and aged between six months to 20 years, with cutaneous skin lesion suggestive of dermatophytosis. Out of these 102 horses sampled, 18 (17.6\%) of the samples were positive for dermatophytes. Majority (33.3\%) of the dermatophytes were isolated from the saddle area (Table 1). The dermatophytes were distributed across two genera Microsporum and Trichophyton and 10 different species (Table 2). Trichophyton verrucosum was the most commonly occurring 
TABLE 2: Species distribution of dermatophytes isolated from different anatomical sites of horses with cutaneous skin lesions in Kaduna State, Nigeria.

\begin{tabular}{|c|c|c|c|}
\hline $\begin{array}{l}\text { Anatomical } \\
\text { location on the } \\
\text { body }\end{array}$ & Total number of isolates & Species of dermatophytes isolated & Number of species of dermatophytes isolated \\
\hline Head & 1 & M. fulvum & 1 \\
\hline \multirow{3}{*}{ Limbs } & \multirow{3}{*}{5} & T. verrucosum & 3 \\
\hline & & M. gypseum & 1 \\
\hline & & T. mentagrophytes & 1 \\
\hline Rump & 1 & T. verrucosum & 1 \\
\hline \multirow{4}{*}{ Saddle area } & \multirow{4}{*}{5} & M. equinum & 2 \\
\hline & & M. canis & 1 \\
\hline & & T. equinum & 1 \\
\hline & & M. gypseum & 1 \\
\hline \multirow{3}{*}{ Flank and girth } & \multirow{3}{*}{3} & M. equinum & 1 \\
\hline & & T. soudanense & 1 \\
\hline & & M. gallinae & 1 \\
\hline \multirow{2}{*}{ Generalized } & \multirow{2}{*}{3} & M. canis & 1 \\
\hline & & T. vanbreuseghemii & 2 \\
\hline
\end{tabular}

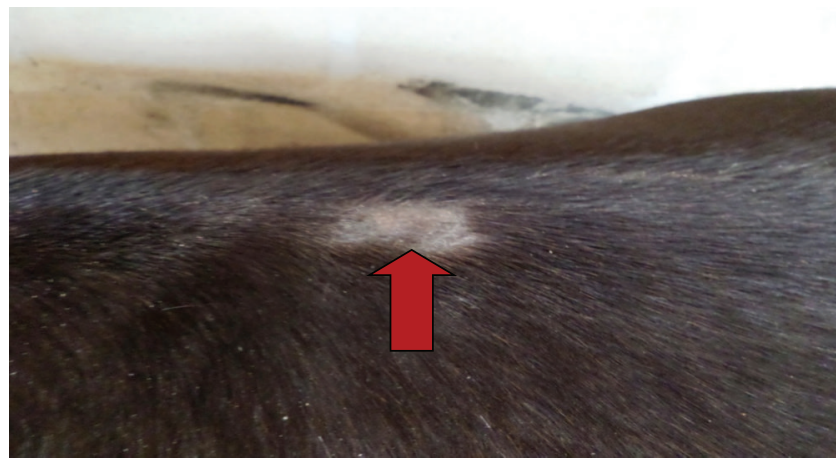

(a)

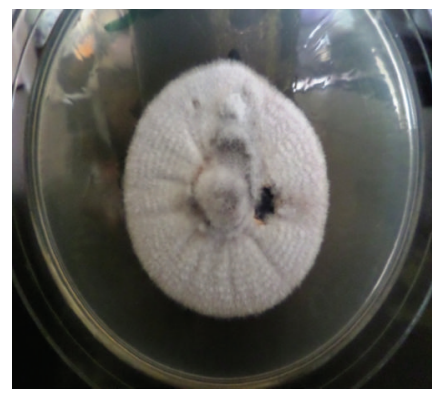

(b)

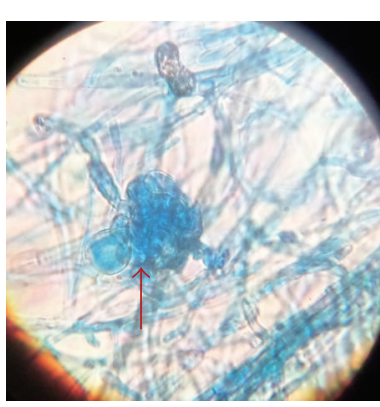

(c)
Figure 1: Single area of patchy alopecia in the saddle region of a horse caused by T. equinum (a), colony of T. equinum (8 days) (b), and nodular bodies and microconidia of T. equinum (c) $(\mathrm{LCB} \times 400)$.

dermatophytes with a frequency of four and occurred mostly on the limbs and rump, with areas of inflammation (kerion) (Figures 1-10). This was followed closely by Microsporum equinum (Figure 1) which was isolated from lesions on the
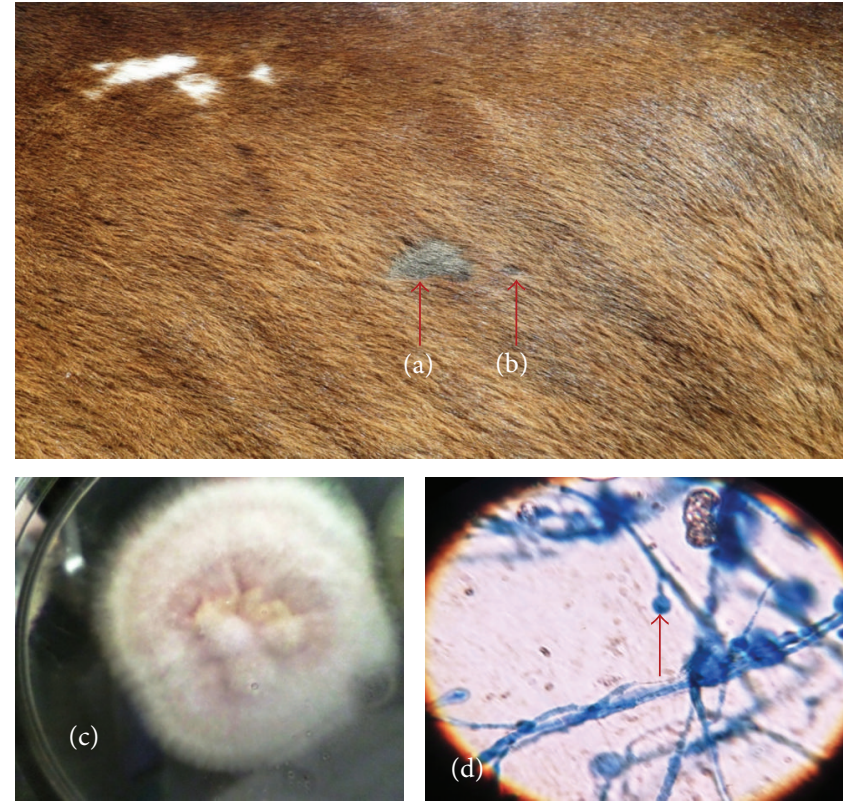

FIGURE 2: Picture showing circumscribed area of alopecia caused by M. gallinae on the flank of a horse (a), a satellite lesion (b), pink to cream tinged colony of M. gallinae (c), and pyriform microconidia of M. gallinae $(\mathrm{d})(\mathrm{LCB} \times 400)$.

saddle, flank, and girth areas (pressure areas). T. Sudanense (Figure 7), an anthropophilic dermatophyte, was isolated from the girth area of a horse. Lesions were found to be areas of patchy alopecia. Lesions of dermatophytosis and isolates were found on the limbs and saddle areas (5 isolates each) followed by the flanks of horses ( 2 isolates) while the least was on the head and rump (1 isolate each) (Table 2 ). 


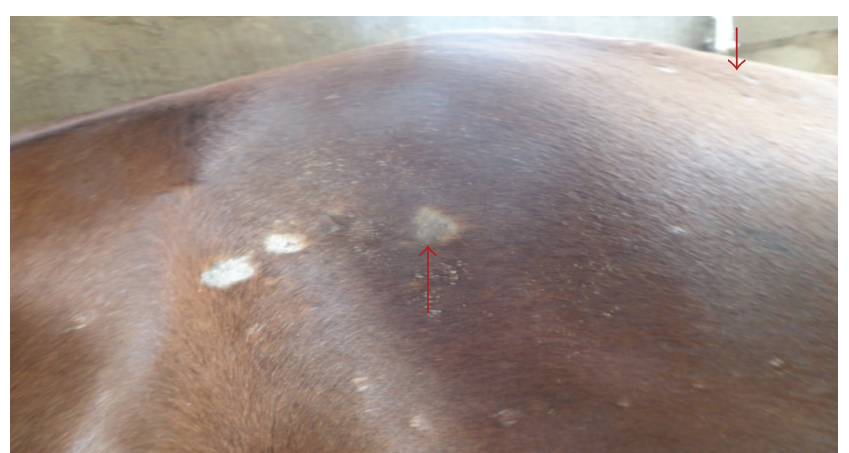

(a)

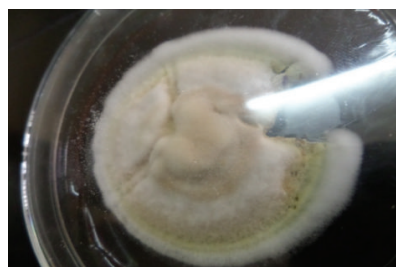

(b)

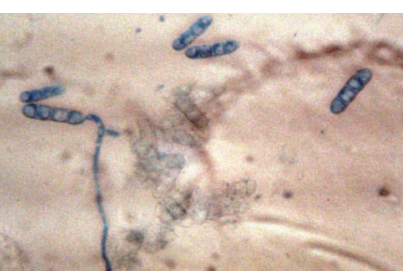

(c)
FIgURE 3: Generalized areas of alopecia on a horse, giving it a "moth eaten" appearance caused by T. vanbreuseghemii (a), colony of $T$. vanbreuseghemii (17 days) (b), microscopy of T. vanbreuseghemii $($ LCB $\times 400)$ showing four-celled club-shaped macroconidia, and microconidia (c).

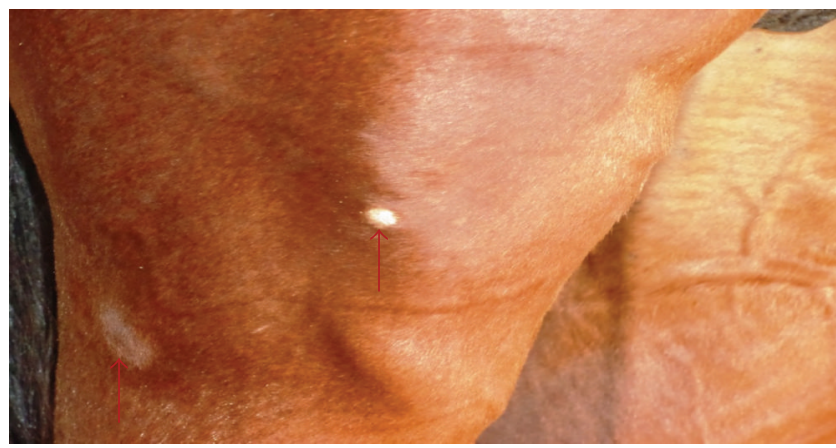

(a)

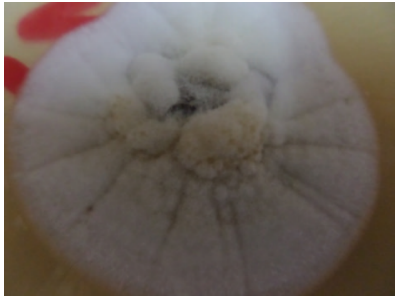

(b)

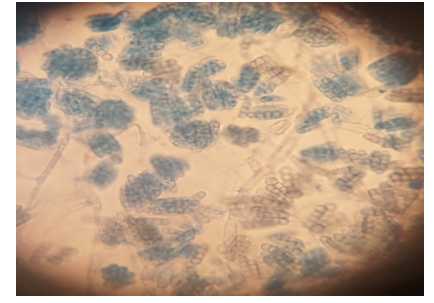

(c)
FIgURE 4: Lesions of dermatophytosis on the hind limb of a horse caused by M. gypseum (a), cream colony of M. gypseum with radial grooves and a central umbo (b), and multiple 4- celled macroconidia of M. gypseum in clusters (c).

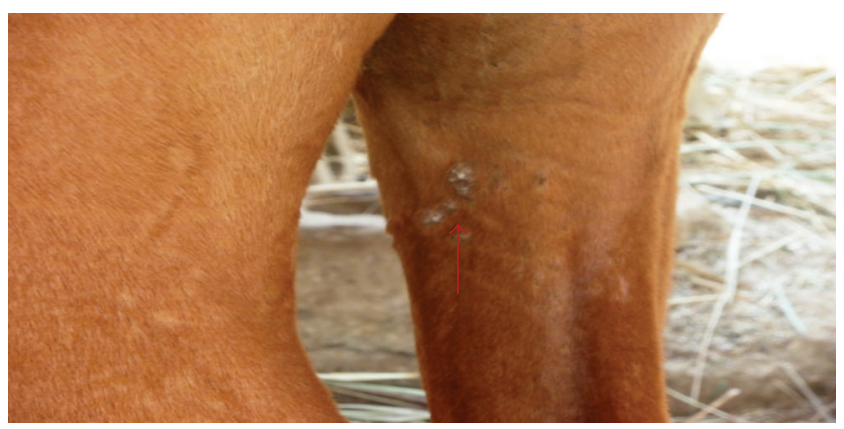

(a)

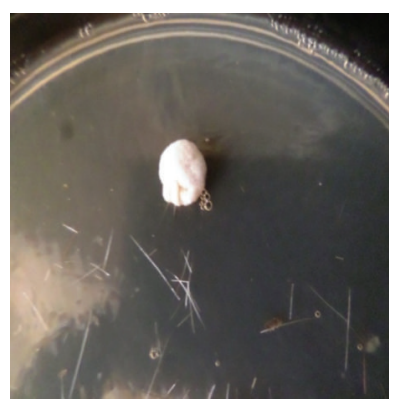

(b)

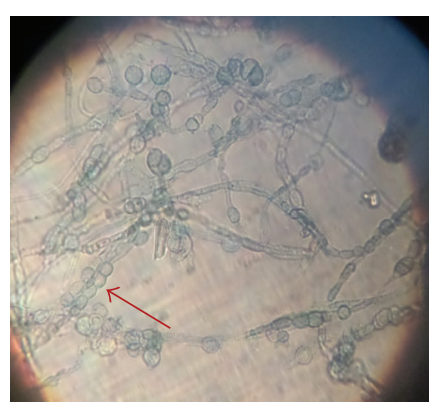

(c)
FIGURE 5: Dermatophytosis caused by T. verrucosum on the limb of a horse (a), slow growing button shaped colony of T. verrucosum (12 days) $(\mathrm{b})$, and chlamydospores in chains $(\mathrm{c})(\mathrm{LCB} \times 400)$.
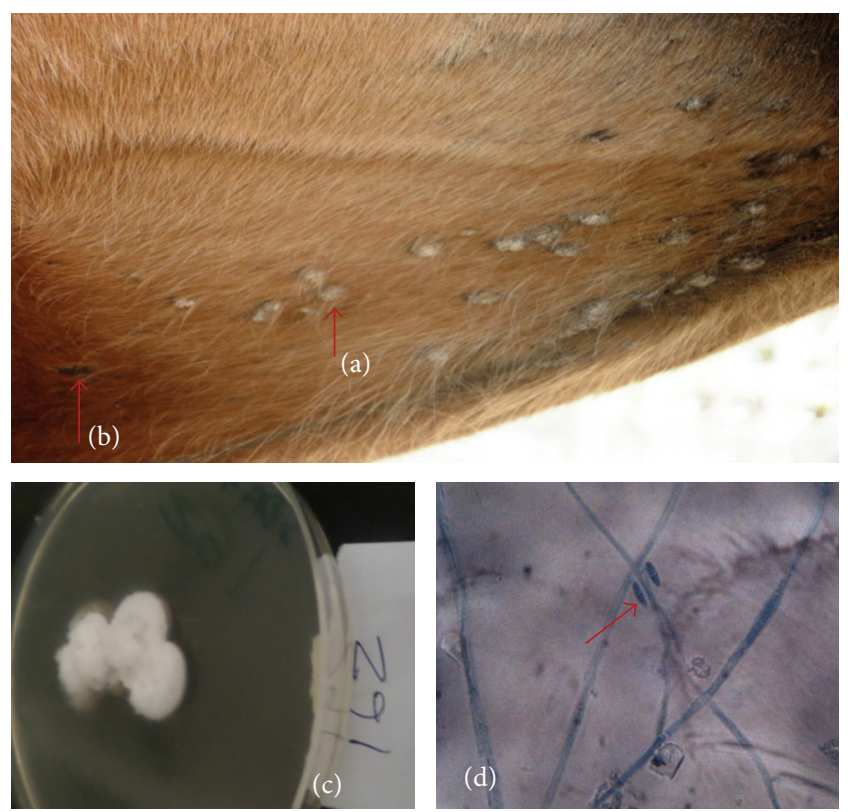

FIGURE 6: Discrete, raised areas of crusting (a), progressing to areas of patchy alopecia on the girth region of a horse caused by $M$. equinum (b), downy colony of $M$. equinum (c), and two-celled thick walled spindle shaped macroconidia of $M$. equinum (d). 


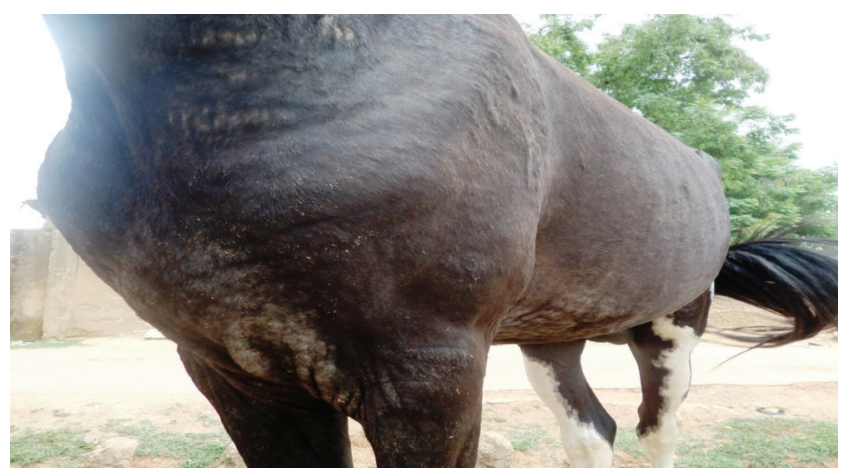

(a)

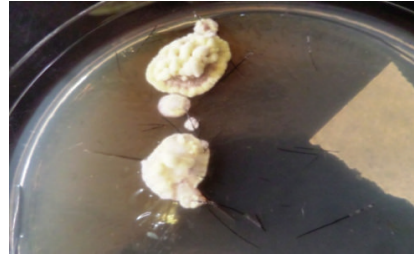

(b)

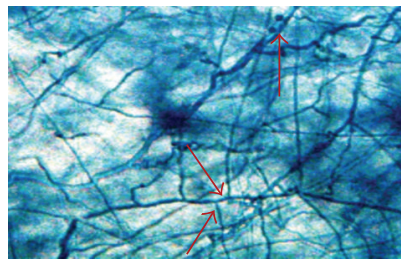

(c)
Figure 7: Areas of hyperkeratosis and alopecia caused by T. sudanense (a), yellow to apricot heaped granular colony of T. sudanense (b), and few globuse microconidia with right angle branching hyphae $(\mathrm{c})(\mathrm{LCB} \times 400)$.

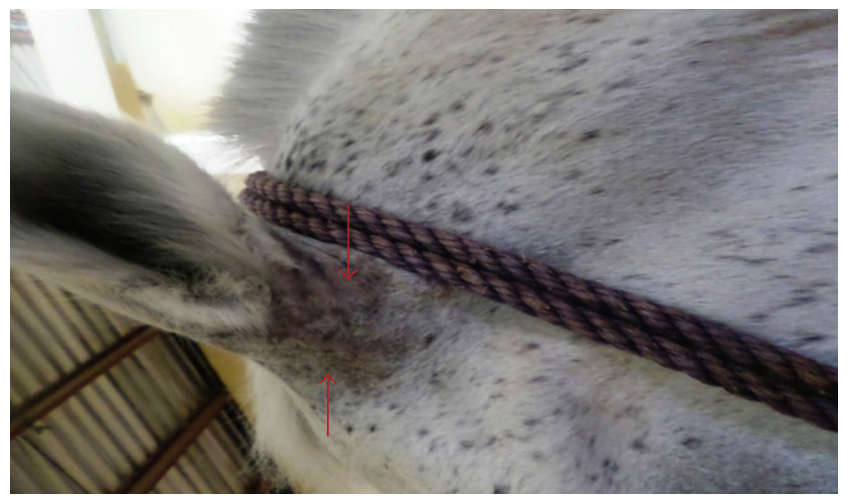

(a)

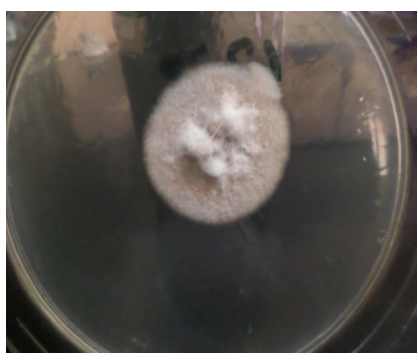

(b)

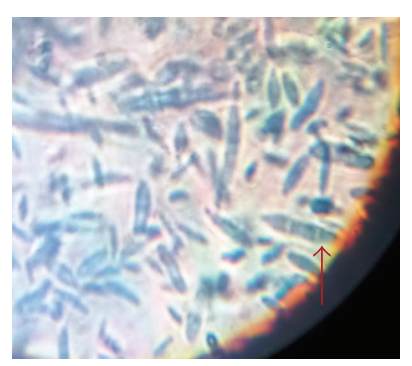

(c)
FIgURE 8: Area of alopecia on the base of an ear of a horse from which $M$. fulvum was isolated (a), pinkish-buff colony of $M$. fulvum (8 days) with central white tuft of mycelium (b), and one- to threecelled macroconidia with tapered ends $(\mathrm{c})(\mathrm{LCB} \times 400)$.

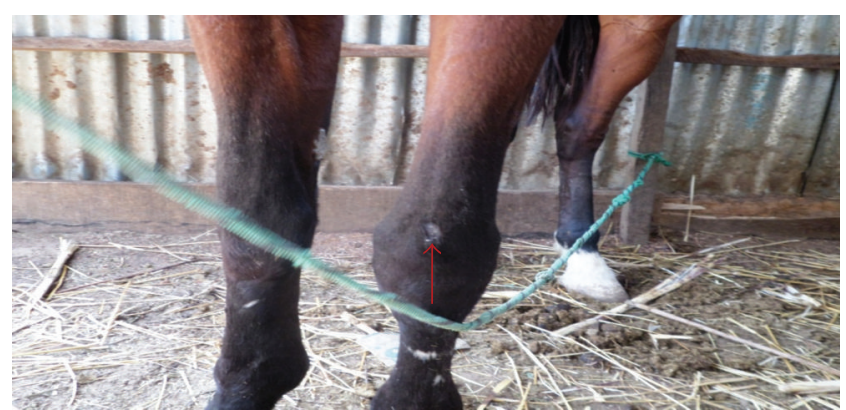

(a)

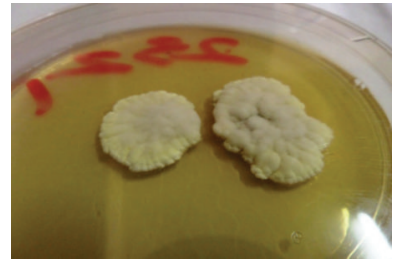

(b)

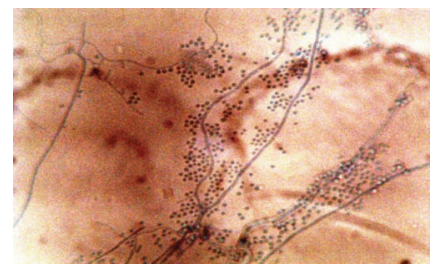

(c)
Figure 9: Lesion caused by T. mentagrophytes on the limb of a horse (a), granular colony of T. mentagrophytes (b), and typical microconidia of T. mentagrophytes "bunch of grapes" formation (c) $(\mathrm{LCB} \times 400)$.

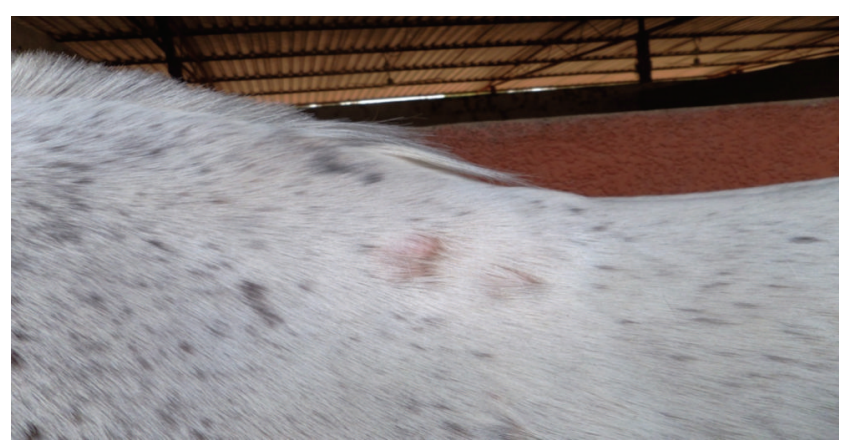

(a)

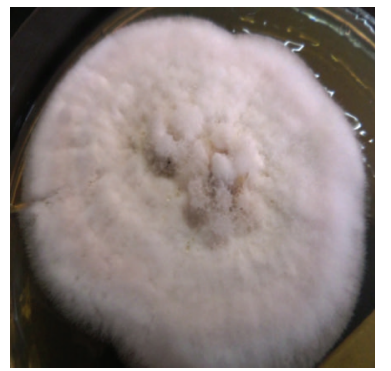

(b)

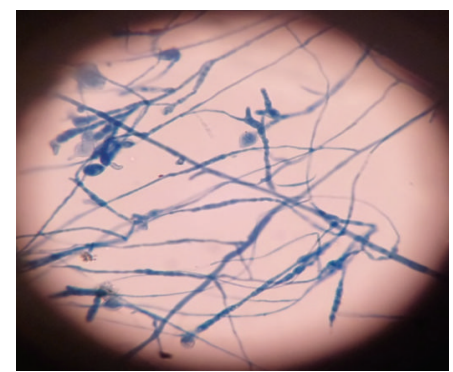

(c)
FIGURE 10: Multiple areas of alopecia on the back of a horse caused by $M$. canis (a), colony of $M$. canis (17 days) (b), and microscopy of $M$. canis showing curved spindle shaped macroconidia with a few distorted, and chlamydospores $(\mathrm{c})(\mathrm{LCB} \times 400)$. 


\section{Discussion}

Lesions suggestive of dermatophytosis in this study were areas of scaling, crusting, and alopecia with some kerion formation as dermatophytes are known to digest the skin, hair, and hoof of animals as a source of carbon using proteolytic and lipolytic enzymes [2]. The lesions were found to occur mostly on the limbs and pressure areas, which is in agreement with other authors [20]. The annular and coalesced lesions expanding centrifugally and losing their circular appearance observed on some horses have been reported to be the characteristic of Trichophyton infection in horses [21]. Dermatophytes are one of the commonest skin diseases affecting horses [22]. Species of dermatophytes belonging to the Trichophyton and Microsporum genera were the major dermatophytes detected in this study. This finding is in agreement with the reports of previous studies that dermatophytes in horses are majorly caused by members of these 2 genera [22]. Similar species of dermatophytes with the exception of T. soudanense detected in this study have also been isolated from horses in other parts of the world [23].

Dermatophytes from the three ecological groups were isolated in this study, M. gypseum, M. fulvum, and T. vanbreuseghemii which are geophilic dermatophytes were isolated from different parts of the body and may have infected the horses directly from the soil and through spores infested fomites as they were all housed in different stables; another source of infection could have been asymptomatic carriers in the stables. T. verrucosum and M. equinum were the most common dermatophytes detected in this study a finding that is consistent with the reports that these agents are the common cause of equine dermatophytosis [22]. The zoophilic T. verrucosum could have been contracted from large herds of cattle that can be found in this region that usually share pasture with the horses [1]. T. mentagrophytes isolated from the limb of a horse could have been contracted from rodents that have free rein of the stables and M. canis from dogs, cats, or any other domestic animals as they have been reported to be the most common dermatophyte encountered in domestic animals in the region [1]. T. soudanense, an anthropophilic dermatophyte which is believed to be strictly human pathogen, was encountered in this study in a horse with extensive inflammation extending from the flank to the ventrum of the horse. This could be attributed to the close contact that exists between these horses and humans. The close contact that exists during grooming, riding, and exercising of the horse may have predisposed it to infection with the anthropophilic dermatophyte. This dermatophyte has previously been isolated from prepubescent children in Nigeria by Nweze [24]. In addition other dermatophytes detected such as M. gypseum, M. canis, T. verrucosum, T. equinum, and T. mentagrophytes have been isolated from cases of tinea capitis and tinea corporis among humans in Nigeria indicating the zoonotic potential of the prevalent dermatophytes [25-27]. The close contact that exists between humans and these horses especially during riding, grooming, and sporting events may result in transmission of these zoophilic dermatophytes from the horses to humans.
The detection of dermatophytes in only $17.6 \%$ of the horses suggests a role of other agents and factors in the observed cutaneous skin lesions. Poor nutrition and management, infectious diseases such as helminthosis, Staphylococcus aureus, infection sweat rash produced by bacteria infection of the hair follicles, allergy, and pruritis produce cutaneous lesions similar to dermatophytosis and may account for some of the skin lesions observed [28].

In conclusion, dermatophytes belonging to two genera (Microsporum and Trichophyton) were isolated from 17.6\% $(18 / 102)$ of the horses with cutaneous skin lesions suggestive of dermatophytosis. T. verrucosum was the most commonly occurring dermatophytes followed by M. equinum. T. soudanense a human dermatophyte was also isolated from one of the horses a finding that suggests a potential public health concern due to the degree of close contact between man and animals in this part of the world. Hence, it is recommended that a wide scale study encompassing different species of domestic animals in different parts of the country be carried out as this will provide more information on the role of dermatophytes in the skin lesions of animals in this environment.

\section{Competing Interests}

The authors declare no conflict of interests.

\section{References}

[1] E. I. Nweze, "Dermatophytoses in domesticated animals," Revista do Instituto de Medicina Tropical de Sao Paulo, vol. 53, no. 2, pp. 95-99, 2011.

[2] K. Ural, B. Yağc1, and N. Ocal, "Cellular enzyme values in hunter/jumper and dressage horses with dermatophytosis," Arquivo Brasileiro de Medicina Veterinaria e Zootecnia, vol. 61, no. 5, pp. 1233-1237, 2009.

[3] B. Havlickova, V. A. Czaika, and M. Friedrich, "Epidemiological trends in skin mycoses worldwide," Mycoses, vol. 51, no. 4, pp. 2$15,2008$.

[4] R. Chermette, L. Ferreiro, and J. Guillot, "Dermatophytoses in animals," Mycopathologia, vol. 166, no. 5-6, pp. 385-405, 2008.

[5] K. J. Kwon-Chung and J. B. Bennett, Medical Mycology, Lea and Febiger, Philadelphia, Pa, USA, 1992.

[6] A. B. Macura, "Dermatophyte infections," International Journal of Dermatology, vol. 32, no. 5, pp. 313-323, 1993.

[7] O. Male, "The significance of mycology in medicine," in Frontiers in Mycology, D. L. Hawksworth, Ed., pp. 131-156, CAB International, Wallingford, UK, 1990.

[8] C. Cafarchia, L. A. Figueredo, and D. Otranto, "Fungal diseases of horses," Veterinary Microbiology, vol. 167, no. 1-2, pp. 215-234, 2013.

[9] E. Seker and N. Dogan, "Isolation of dermatophytes from dogs and cats with suspected dermatophytosis in Western Turkey," Preventive Veterinary Medicine, vol. 98, no. 1, pp. 46-51, 2011.

[10] C. Cafarchia, S. Weigl, L. A. Figueredo, and D. Otranto, "Molecular identification and phylogenesis of dermatophytes isolated from rabbit farms and rabbit farm workers," Veterinary Microbiology, vol. 154, no. 3-4, pp. 395-402, 2012.

[11] R. W. Riddell, "Permanent stained mycological preparations obtained by slide culture," Mycologia, vol. 42, no. 2, pp. 265-270, 1950. 
[12] D. W. R. Mackenzie, “'Hairbrush diagnosis' in detection and eradication of non-fluorescent scalp ringworm," The British Medical Journal, vol. 2, no. 5353, pp. 363-365, 1963.

[13] J. Adekeye, P. Addo, C. N. Kwanashie et al., "Prevalence of animal dermatophytes in Zaria," Zariya Veterinarian, vol. 4, no. 1, pp. 83-86, 1989.

[14] B. E. Elewski, "Onychomycosis; pathogenesis, diagnosis and management," Clinical Microbiology Reviews, vol. 11, no. 3, pp. 415-425, 1995.

[15] M. Sharma, M. Sharma, R. Shri, and N. A. V. Nagar, "Influence of culture media on mycelial growth and sporulation of some soil dermatophytes compared to their clinical isolates," Journal of Microbiology Antimicrobial, vol. 3, no. 8, pp. 196-200, 2011.

[16] R. Robert and M. Pihet, "Conventional methods for the diagnosis of dermatophytosis," Mycopathologia, vol. 166, no. 5-6, pp. 295-306, 2008.

[17] D. Ellis, D. Stephen, A. Helen, H. Rosemary, and B. Robyn, Descriptions of Medical Fungi, Mycology Unit Women's and Children's Hospital School of Molecular \& Biomedical Science University of Adelaide, Adelaide, Australia, 2nd edition, 2007.

[18] I. Weitzman and R. C. Summerbell, "The dermatophytes," Clinical Microbiology Reviews, vol. 8, no. 2, pp. 240-259, 1995.

[19] N. A. Issa and I. K. Zangana, "Isolation of Trichophyton mentogrophytes var mentogrophytes from naturally infected laboratory albino rats: experimental infection and treatment in rabbits," Iraqi Journal of Veterinary Sciences, vol. 23, no. 2, pp. 29-34, 2009.

[20] J. Weeks, S. A. Mosser, and B. E. Elewski, "Superficial cutaneous fungal infections," in Clinical Mycology, W. E. Dismukes, G. E. Pappas, and J. D. Sobel, Eds., pp. 370-373, Oxford University Press, New York, NY, USA, 2003.

[21] O. M. Radostis, D. C. Blood, and C. C. Gay, Veterinary Medicine, Bailliere Tindall, London, UK, 8th edition, 1997.

[22] R. C. Pilsworth and D. Knottenbelt, "Dermatophytosis (ringworm)," Equine Veterinary Education, vol. 19, no. 3, pp. 151-154, 2007.

[23] A. M. Ahdy, M. Z. Sayed-Ahmed, E. E. Younis, H. N. Baraka, and S. A. El-khodery, "Prevalence and potential risk factors of dermatophytosis in Arabian horses in Egypt," Journal of Equine Veterinary Science, vol. 37, no. 1, pp. 71-76, 2016.

[24] E. I. Nweze, "Etiology of dermatophytoses amongst children in northeastern Nigeria," Medical Mycology, vol. 39, no. 2, pp. 181184, 2001.

[25] O. O. Oke, O. Onayemi, O. A. Olasode, A. G. Omisore, and O. A. Oninla, "The prevalence and pattern of superficial fungal infections among school children in ile-ife, south-western nigeria," Dermatology Research and Practice, vol. 2014, Article ID 842917, 7 pages, 2014.

[26] U. C. Ozumba and R. Nlemadim, "Prevalence of dermatophytosis in University of Nigeria Teaching Hospital, Enugu, Nigeria: any change in pattern?" Nigerian Journal of Clinical Practice, vol. 8, no. 2, pp. 83-85, 2005.

[27] S. A. Adefemi, L. O. Odeigah, and K. M. Alabi, "Prevalence of dermatophytosis among primary school children in Oke-oyi community of Kwara state," Nigerian Journal of Clinical Practice, vol. 14, no. 1, pp. 23-28, 2011.

[28] J. S. Weese and A. A. Yu, "Infectious folliculitis and dermatophytosis," Veterinary Clinics Equine, vol. 29, no. 3, pp. 559-575, 2013. 


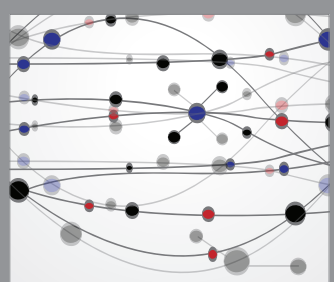

The Scientific World Journal
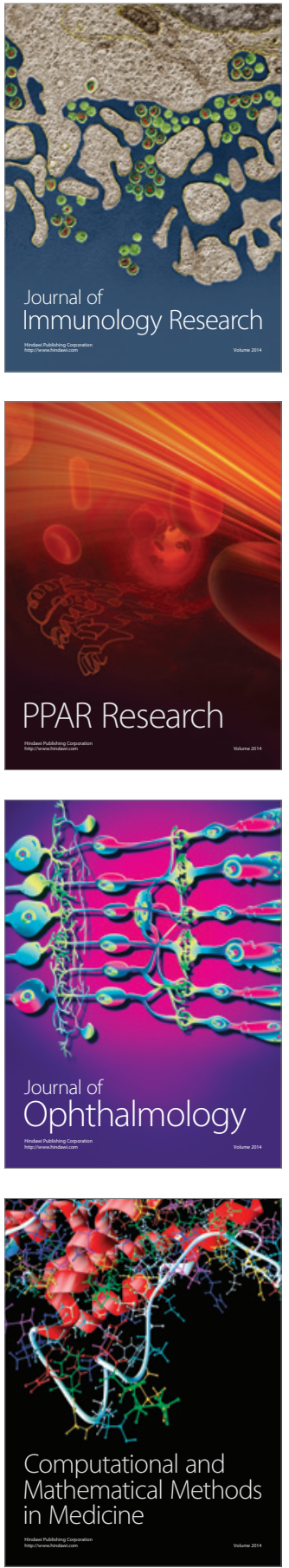

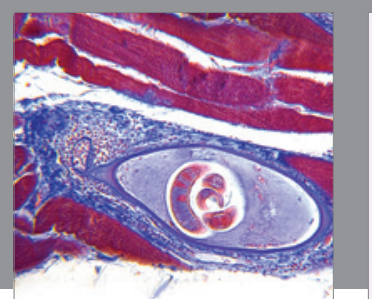

Gastroenterology Research and Practice

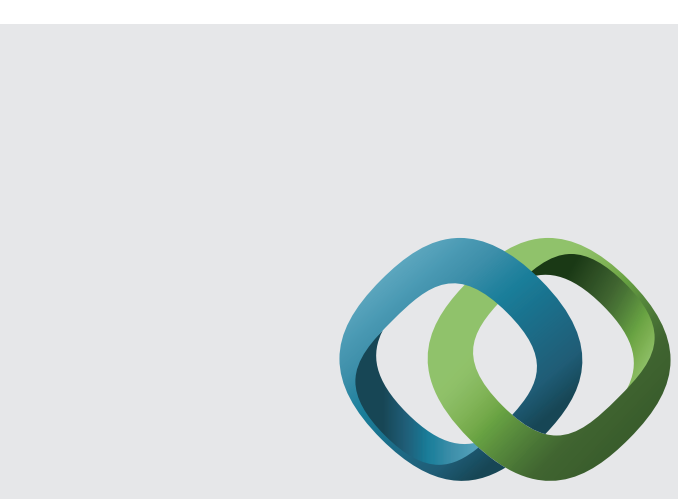

\section{Hindawi}

Submit your manuscripts at

http://www.hindawi.com
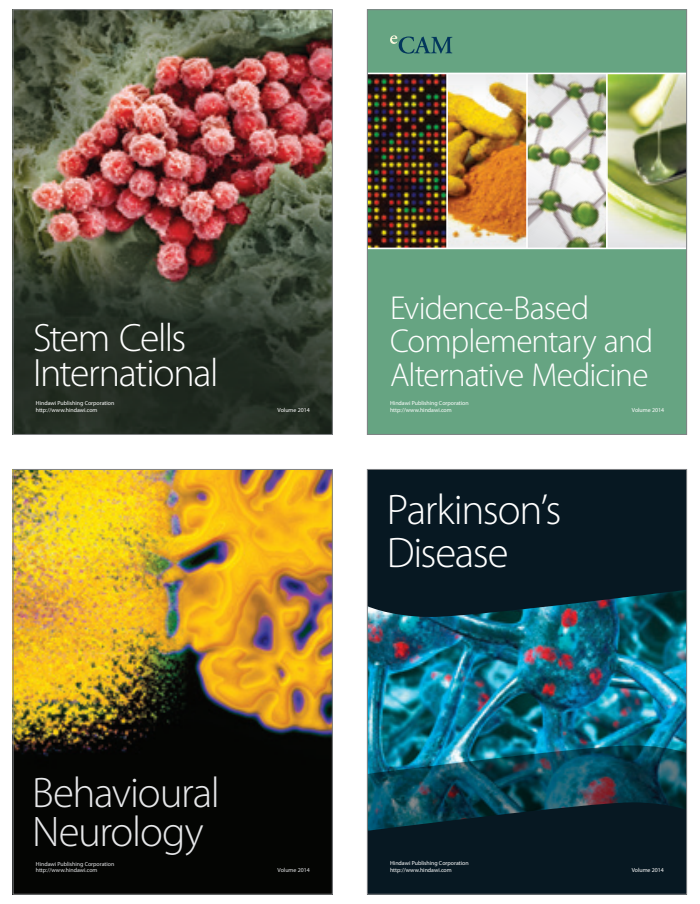
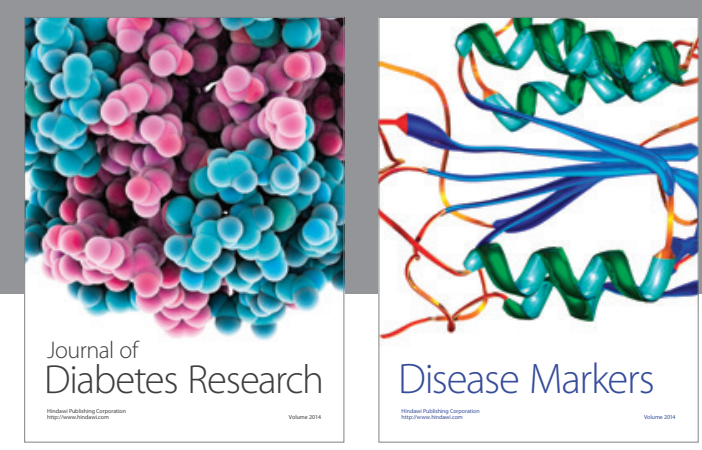

Disease Markers
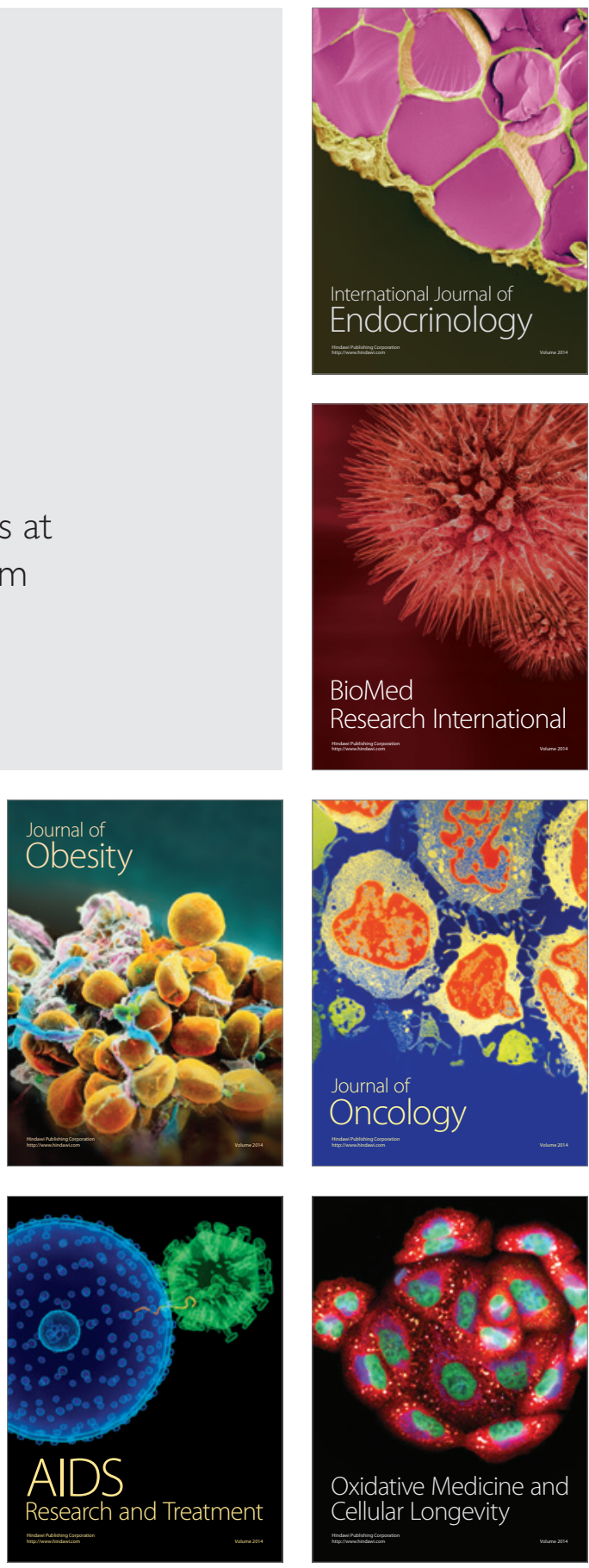